\title{
Suplementary information
}

\section{Impact of Mutation on the Structural Stability and Conformational Landscape of Inhibitor-resistant TEMß-lactamase: A High-performance Molecular Dynamics Simulation Study}

\author{
Sandip K. Mukherjee ${ }^{1}$, Mandira Mukherjee ${ }^{1 *}$ and Padmaja P. Mishra ${ }^{2,3 *}$ \\ ${ }^{1}$ Department of Biochemistry and Medical Biotechnology, Calcutta School of Tropical \\ Medicine, Kolkata \\ ${ }^{2}$ Chemical Science Division, Saha Institute of Nuclear Physics, Kolkata \\ ${ }^{3}$ Homi Bhaba National Institute, Mumbai \\ *email: padmaja.mishra@saha.ac.in
}

Figure S1: Multiple sequence alignment of the wild type (1ZG4) and three IRT variant; AJC64564.1 (pUE184TEM), AJC64567.1 (pUE203TEM), and AJC64568.1 (pUE210TEM). The amino acid position (substitutions at amino acid residues $69,84,165,184,262,276$ ) is marked according to the Amber classification of Class A $\beta$-lactamases.

$1 Z$ G 4

AJC 64567.1

AJC 64564.1

AJC 64568.1

1ZG4

AJC 64567.1

AJC 64564.1

AJC64568.1

1ZG4

AJC 64567.1

AJC 64564.1

AJC 64568.1

1ZG 4

AJC64567.1

AJC 64564.1

AJC64568.1
MS IQHFRVALIPFFAAFCLPVFAHPETLVKVKDAEDQLGARVGY IELDLNSGKILESFRP MS IQHFRVALI P FFAAFCLPVFAHPETLVKVKDAEDQLGARVGY IELDLNSGKILESFRP MS IQHFRVALI PFFAAFCLPVFAHPETLVKVKDAEDQLGARVGY IELDLNSGKILESFRP MS IQHFRVAL I PFFAAFCLPVFAHPETLVKVKDAEDQLGARVGYIELDLNSGKILESFRP

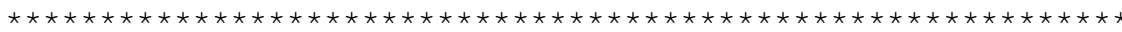

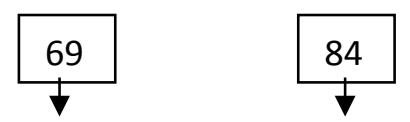

EERFPMMSTFKVLLCGAVLSRIDAGQEQLGRRIHYSQNDLVEYS PVTEKHLTDGMTVREL EERFPMMSTFKVLLCGAVLSRIDAGQEQLGRRIHYSQNDLVEYSPVTEKHLTDGMTVREL EERFPMLSTFKVLLCGAVLSRVDAGQEQLGRRIHYSQNDLVEYS PVTEKHLTDGMTVREL EERFPMMSTFKVLLCGAVLSRVDAGQEQLGRRIHYSQNDLVEYS PVTEKHLTDGMTVREL

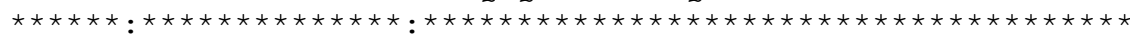

165

CSAAITMS DNTAANLLLTTIGGPKELTAFLHNMGDHVTRLDRWEPELNEA I PNDERDTTM CSAA ITMS DNTAANLLLTT I GGPKELTAFLHNMGDHVTRLDRWEPELNEA I PNDERDTTM CSAAITMSDNTAANLLLTT I GGPKELTAFLHNMGDHVTRLDRGEPELNEA I PNDERDTTM CSAAITMS DNTAANLLLTT IGGPKELTAFLHNMGDHVTRLDRWEPELNEAI PNDERDTTM

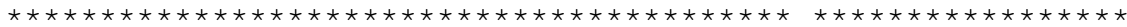

184

PVAMATTLRKLLTGELLTLASRQQLIDWMEADKVAGPLLRSALPAGWFIADKSGAGERGS PVAMATTLRKLLTGELLTLASRQQLIDWMEADKVAGPLLRSALPAGWFIADKSGAGERGS PAAMATTLRKLLTGELLTLASRQQLIDWMEADKVAGPLLRSALPAGWFIADKSGAGERGS PAAMATTLRKLLTGELLTLASRQQLIDWMEADKVAGPLLRSALPAGWFIADKSGAGERGS

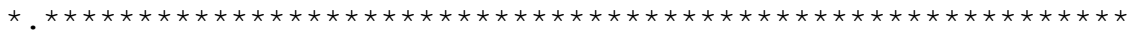


$1 \mathrm{ZG} 4$

AJC 64567.1

AJC 64564.1

AJC 64568.1

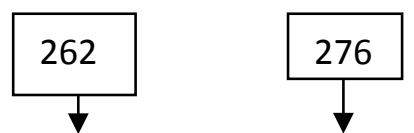

RGIIAALGPDGKPSRIVVIYTTGSQATMDERNRQIAEIGASLIKHW RGRIAALGPDGKPSRIVI IYTTGSQATMDERNRQIAEIGASLIKHW RGRIAALGPDGKPSRIVVIYTTGSQATMDERNRQIAEIGASLIKHW RGRIAALGPDGKPSRIVVIYTTGSQATMDERSRQIAEIGASLIKHW

Figure S2: Replica plots for 100 ns simulation time frame shown for mutant proteins A) pUE184TEM B) pUE203TEM C) pUE210TEM (displayed in replica 1 black, replica 2 red, replica 3 blue). All replica has a very similar pattern to overall simulation time.

A

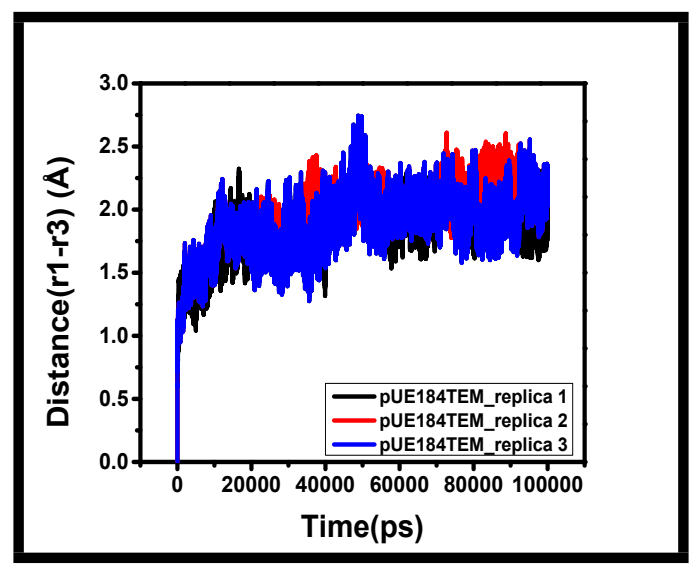

C

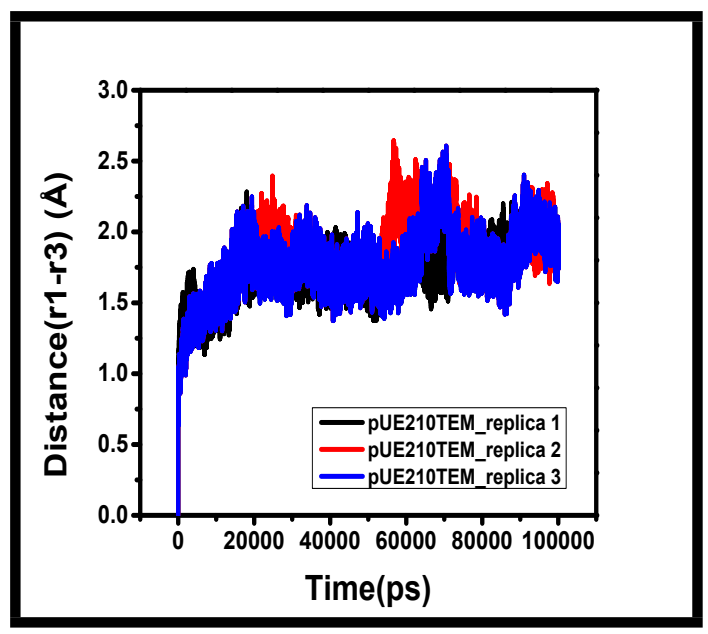

B

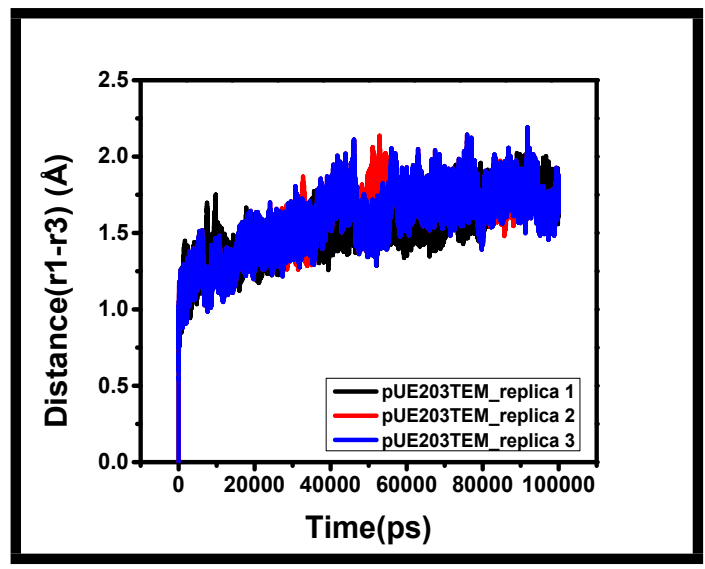


Figure S3: C- $\alpha$ backbone RMSD plots for 100 ns simulation time frame shown for the wild type protein 1ZG4 (displayed in black) in comparison with mutant proteins A) pUE184TEM B) pUE203TEM C) pUE210TEM (displayed in red).

A

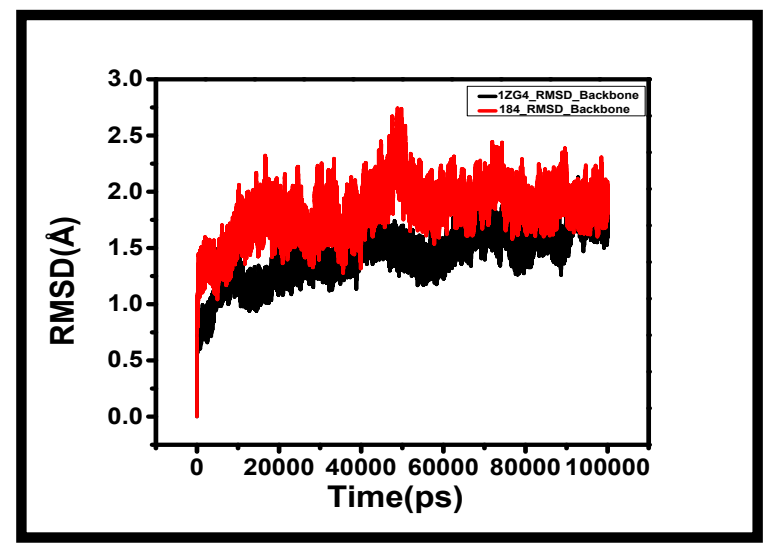

C

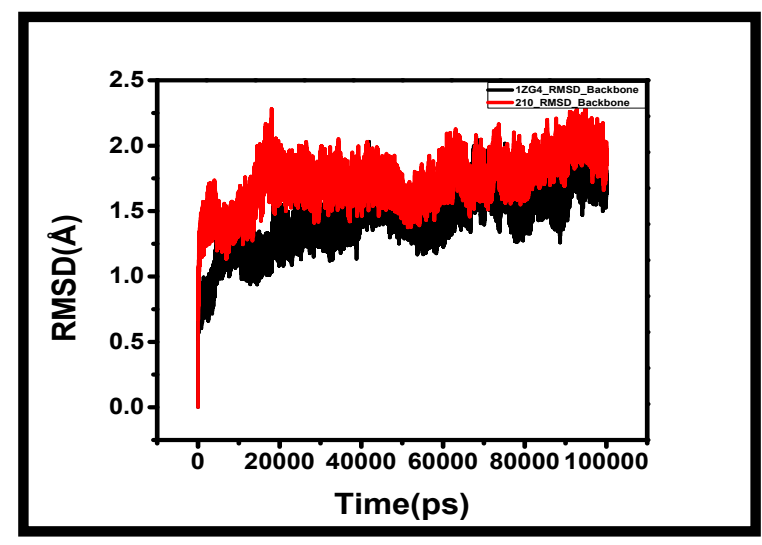

B

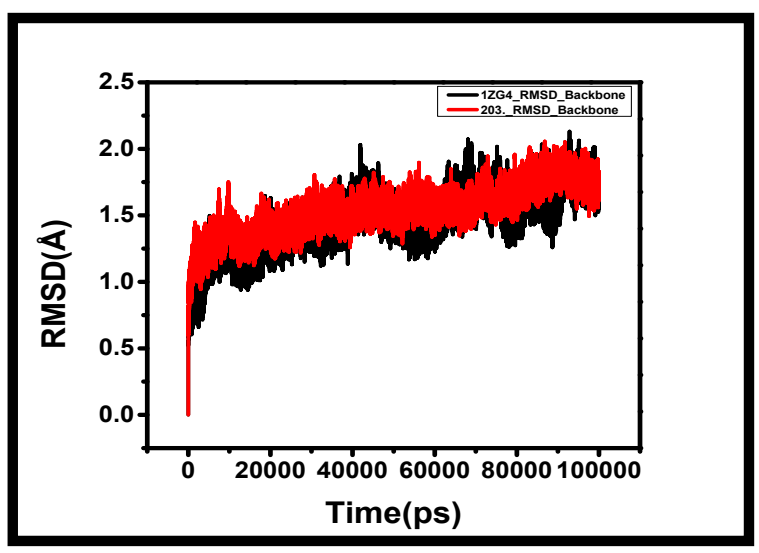


Figure S4: RMSF plots for the backbone $\mathrm{C}-\alpha$ atoms for $100 \mathrm{~ns}$ of the simulation shown for the wild type protein 1ZG4 (displayed in black) in comparison with mutant proteins a) pUE184TEM b) pUE203TEM c) pUE210TEM (displayed in red).

A

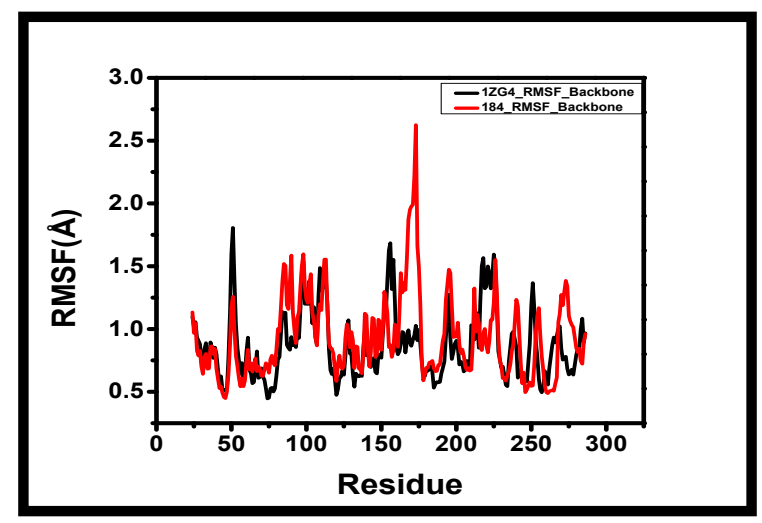

$\mathrm{C}$

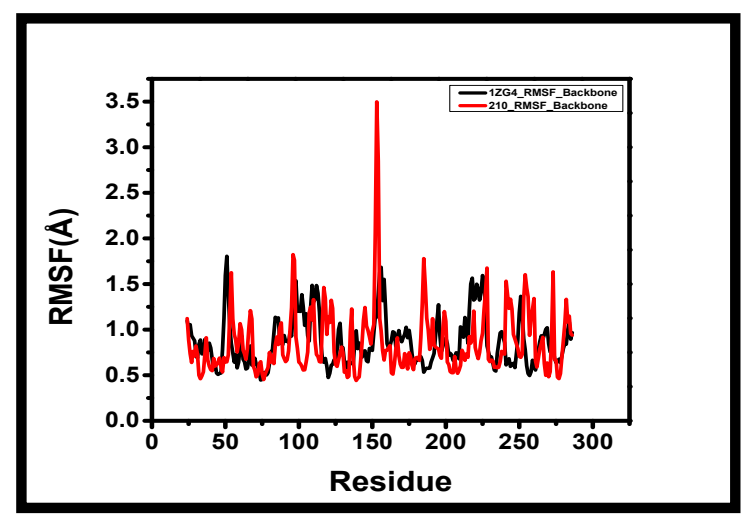

B

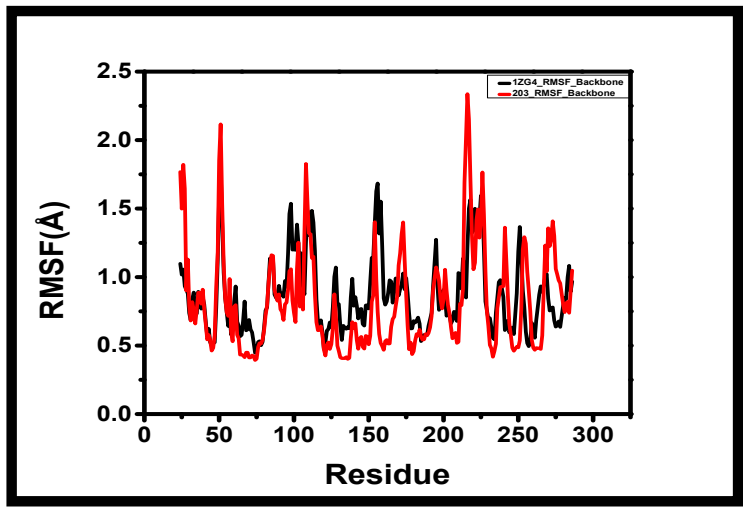


Figure S5: RMSF plots for contact and non-contact residue mobility shown for the wild type protein 1ZG4 (displayed in red) in comparison with mutant proteins A) pUE184TEM B) pUE203TEM C) pUE210TEM (displayed in blue). Contact residues are shown as solid symbols in the plot and arrow indicating opposite side $(\longleftrightarrow \longrightarrow)$ means contact residue are highly mobile and an arrow indicating same side $(\rightarrow \leftarrow)$ means contact residue are less mobile

A

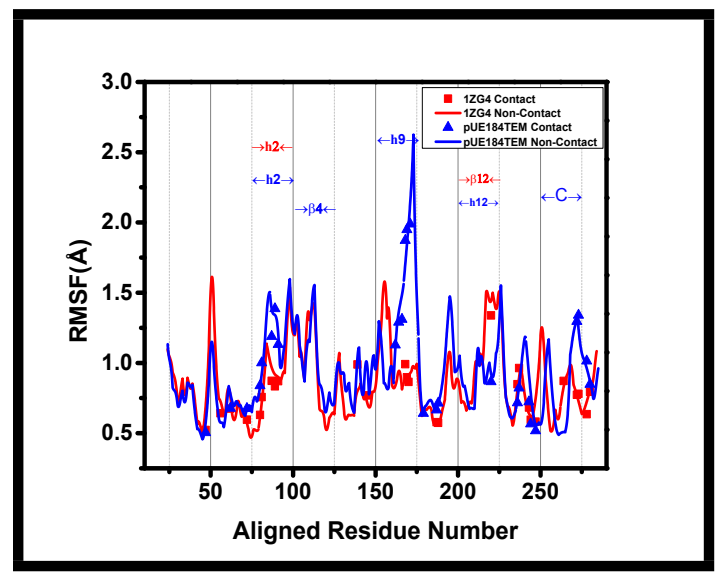

$\mathrm{C}$

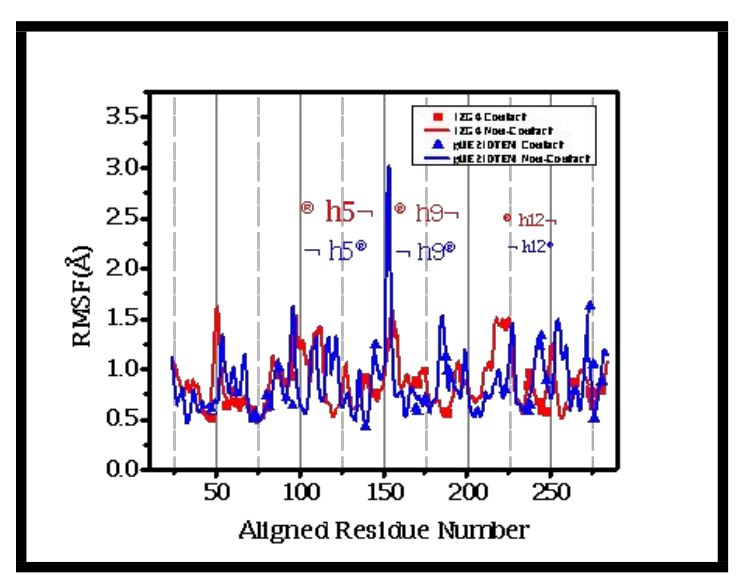

B

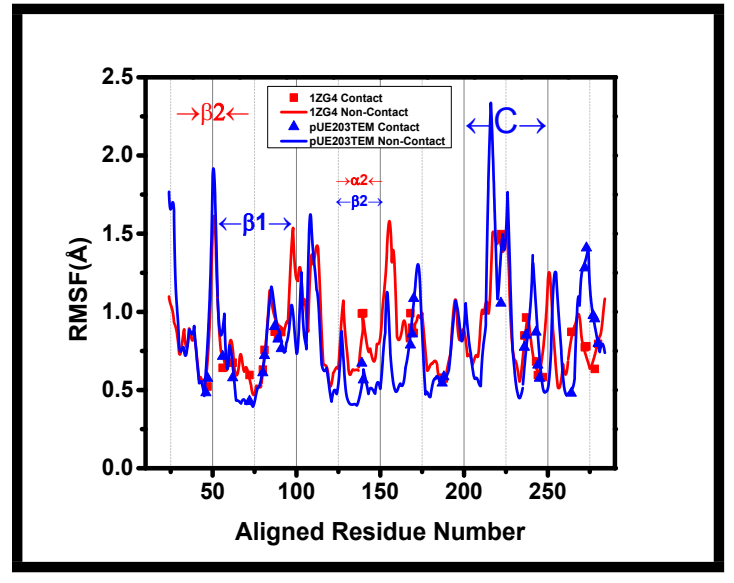


Figure S6 : Radius of gyration for the backbone $\mathrm{C}-\alpha$ atoms for $100 \mathrm{~ns}$ of the simulation shown for the wild type protein 1ZG4 (displayed in black) in comparison with mutant proteins a) pUE184TEM b) pUE203TEM c) pUE210TEM (displayed in red).

A

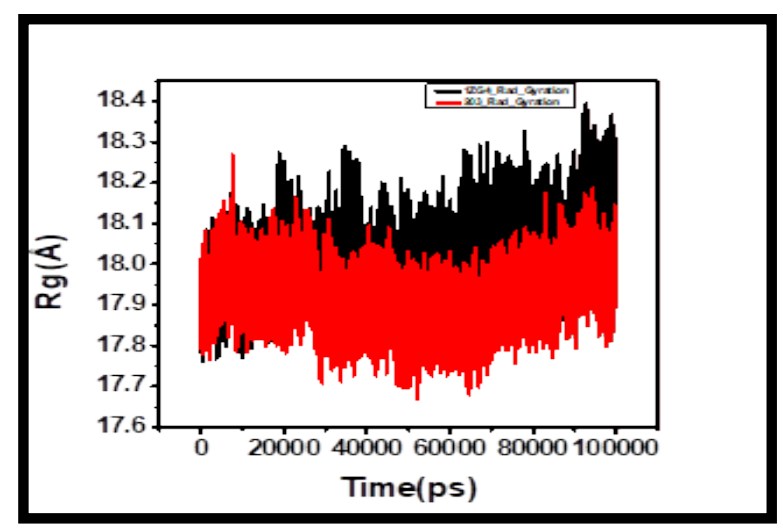

$\mathrm{C}$

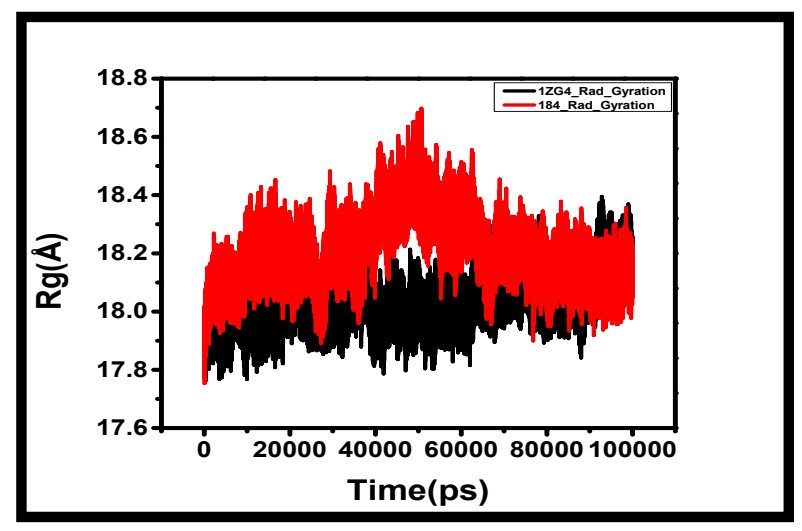

B

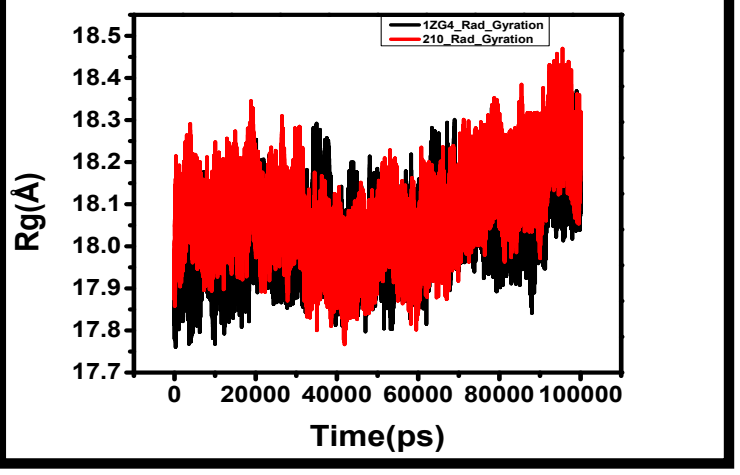


Figure S7: Projection of SSEs throughout the MD simulation trajectory for A)1ZG4 and mutant protein B) pUE184TEM, C) pUE203TEM, D) pUE210TEM) along with comparative snapshots of the simulation trajectory for different nanosecond timescale. Mutated amino acids are marked in yellow in the ribbon diagram of the modeled proteins. SSE composition represented by different color codes from helices; pink, turns; green, 3-10 helix; blue, $\beta$ strands; yellow, coils; white.

A

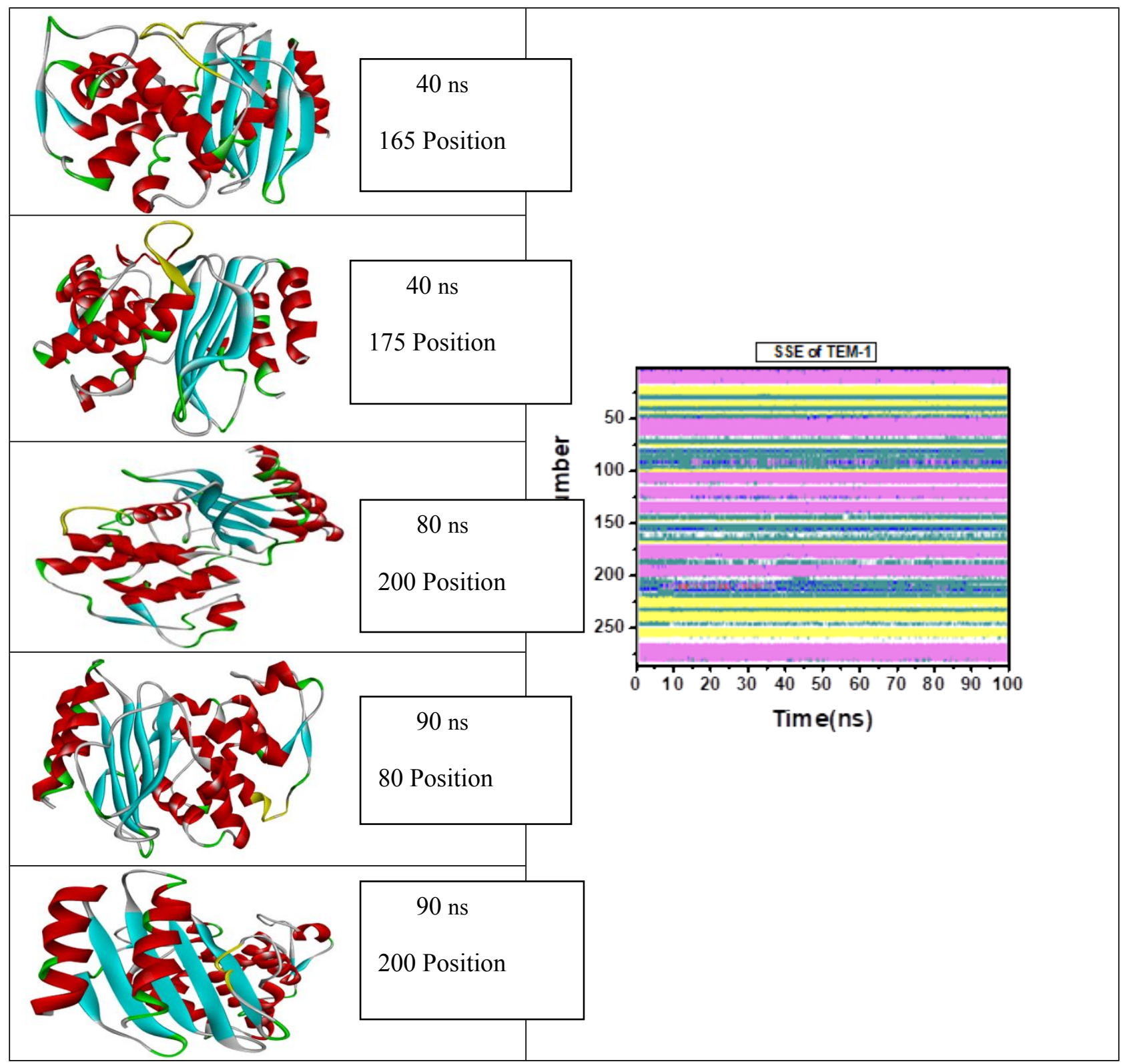


B

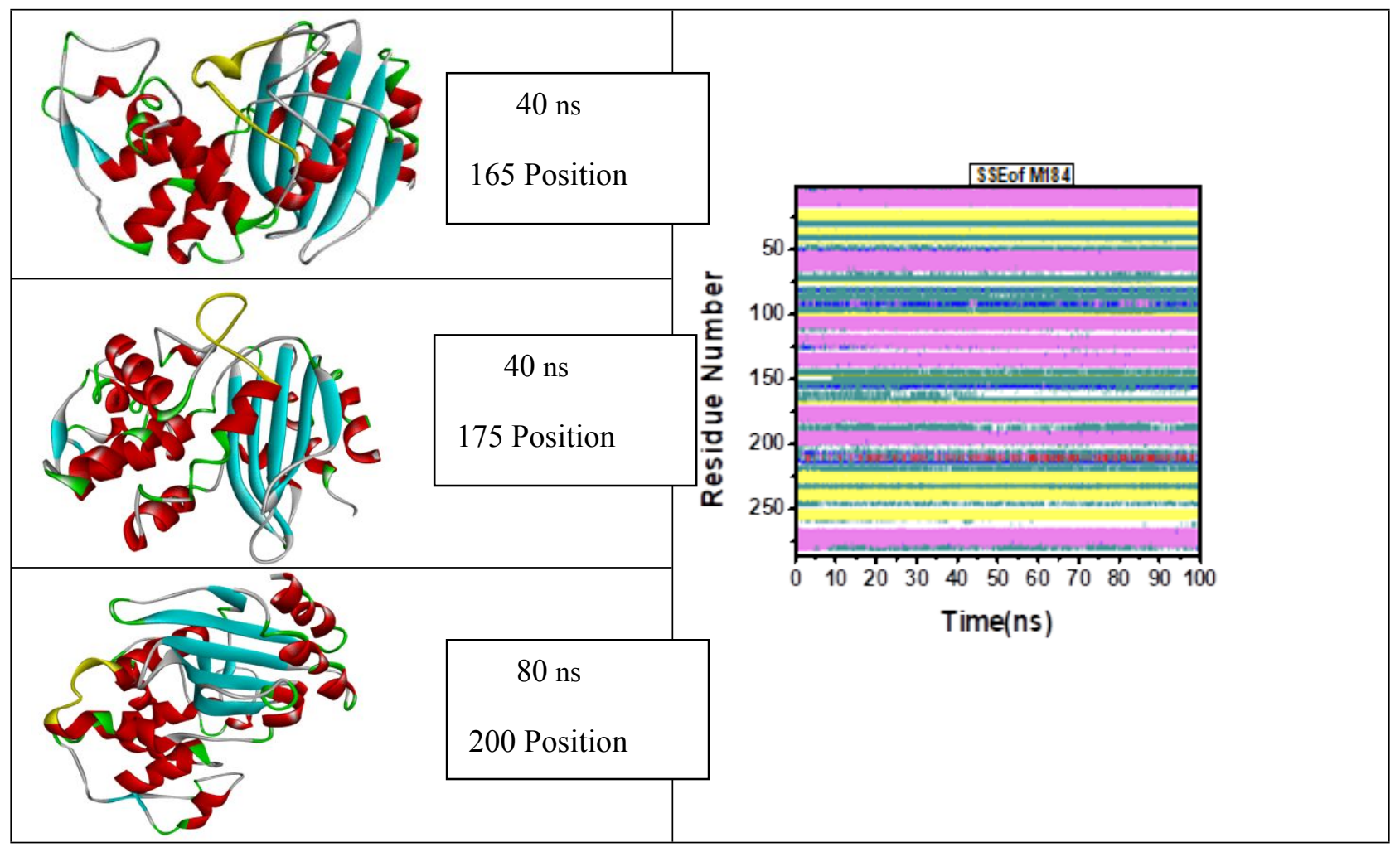

C

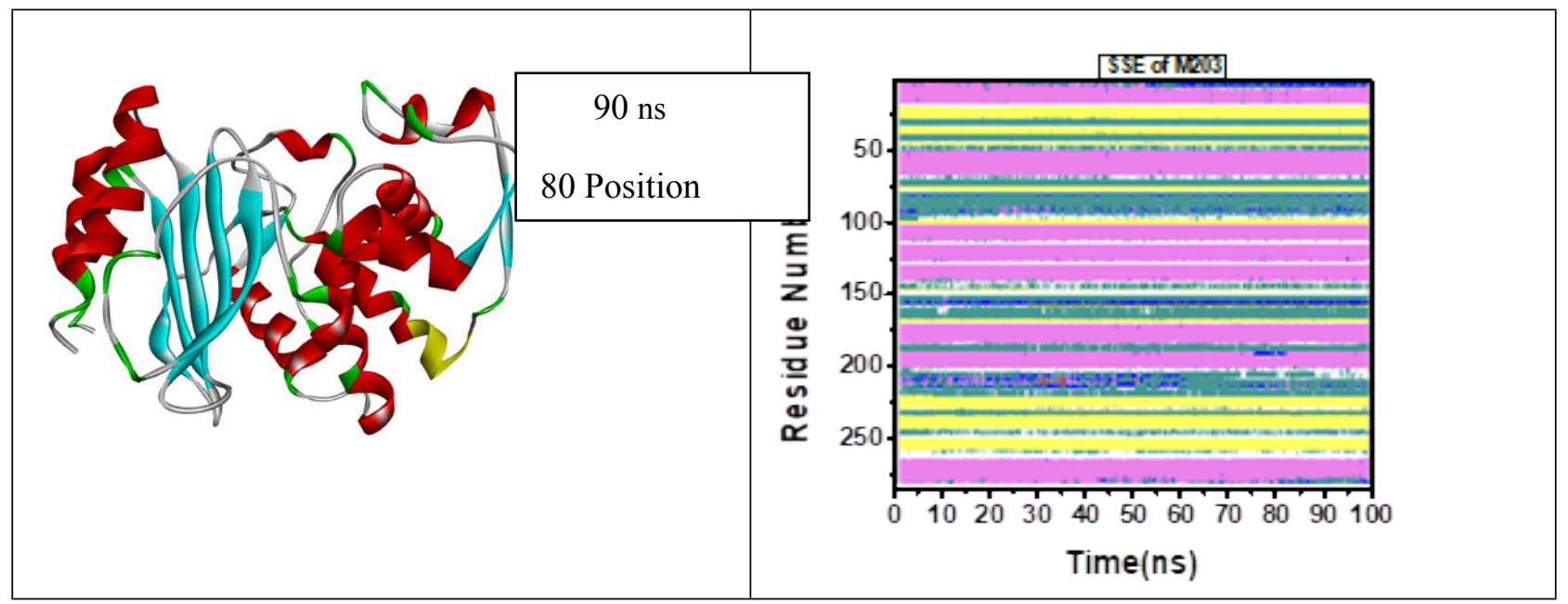


D

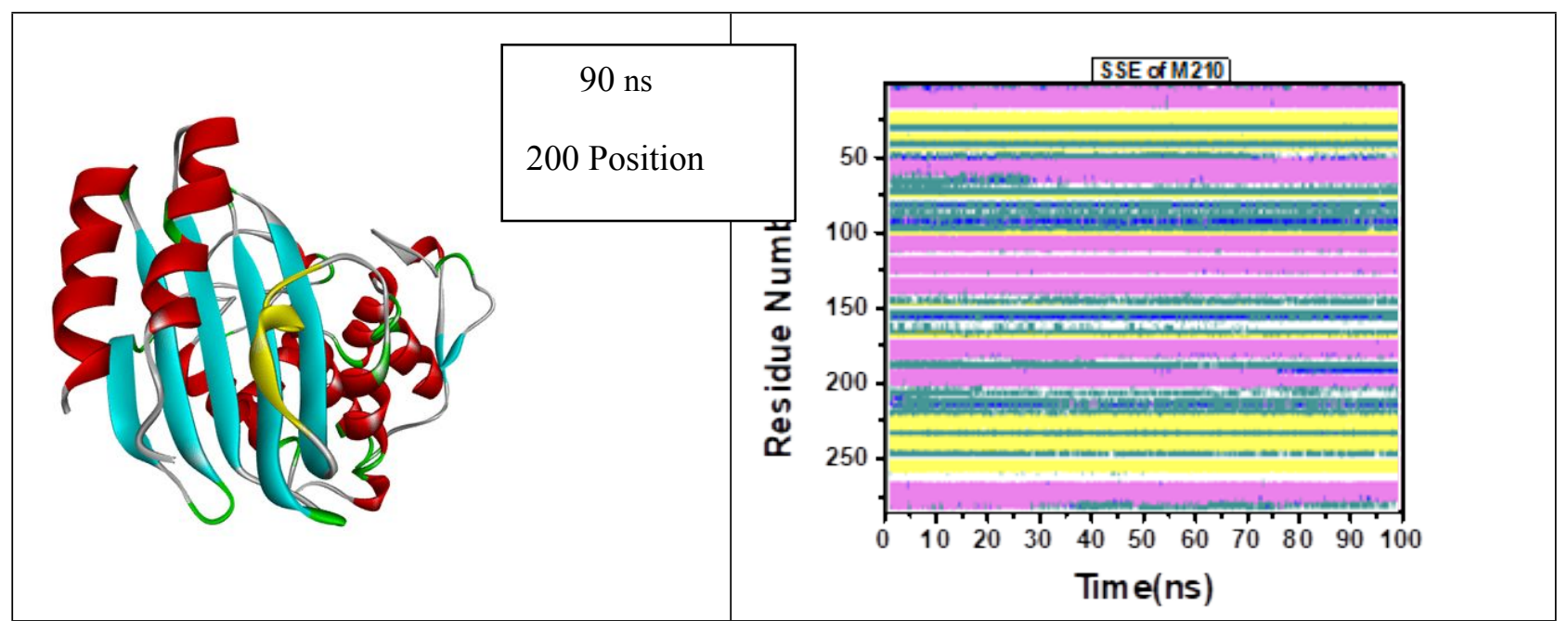

Table S1: Average MD RMSF values for all contact residues with respect to all residues (Standard deviations parenthesis) and enrichment factor (EF) of wild type (1ZG4) and three IRT variants; pUE184TEM, pUE203TEM, pUE210TEM

\begin{tabular}{|c|c|c|c|c|}
\hline Protein & \multicolumn{2}{|c|}{ RMSF $(\AA)$} & \multicolumn{2}{c|}{ Contacts } \\
\hline & All Residues & All Contacts & & \\
\hline & Average & Average & EF & p-value \\
\hline 1ZG4 & $0.87(0.27)$ & $0.77(0.178)$ & 0.105 & 0.048 \\
\hline pUE184TEM & $0.9358(0.325)$ & $1.024(0.424)$ & 1.27 & 0.041 \\
\hline pUE203TEM & $0.8276(0.371)$ & $0.7721(0.2352)$ & 1.14 & 0.03 \\
\hline pUE210TEM & $0.865(0.391)$ & $0.833(0.2912)$ & 1.06 & 0.032 \\
\hline
\end{tabular}

